\title{
Povos indígenas e as relações culturais, econômicas e políticas: reflexões sobre a interculturalidade crítica e a decolonialidade
}

\author{
Indigenous peoples and cultural, economic and political \\ relations: reflections on critical interculturality and \\ decoloniality
}

Matheus Moreira da Silva ${ }^{1}$ José Pedro Machado Ribeiro ${ }^{1}$

Elias Nazareno ${ }^{1}$

DOI: http://dx.doi.org/10.20435/tellus.vi43.684

Resumo: Este artigo tem como objetivo problematizar e comparar interpretações e relatos voltados à interculturalidade crítica, decolonialidade e ecologia de saberes, os quais articulam elementos culturais, epistêmicos, materiais e simbólicos ligados ao papel das mudanças culturais e econômicas dos povos indígenas brasileiros, de diversas etnias, diante dos vários segmentos da sociedade nacional. Lançamos mão de olhares antropológicos, de abordagem hermenêutica, utilizando como opção política e metodológica a pedagogia decolonial, as reflexões próprias, estabelecendo debates significativos para identificar ideias e posturas (também políticas) sobre as imposições do Ocidente ante os povos indígenas. A proposta aqui estabelecida pretende reunir questões vinculadas aos sistemas políticos e comerciais das várias comunidades indígenas e os embates epistemológicos que constituem esses cenários, bem como analisar, em torno da interculturalidade, as mudanças históricas ocasionadas pelos vários segmentos da sociedade nacional.

Palavras-chave: interculturalidade crítica; decolonialidade; povos indígenas; diversidade; comércio.

\begin{abstract}
This article aims to problematize and compare interpretations and reports aimed at critical interculturality, decoloniality and ecology of knowledge, which articulate cultural, epistemic, material and symbolic elements linked to the role of cultural and economic changes of Brazilian indigenous peoples, of different ethnic groups, in view of the various segments of national society. We made use of anthropological views, of a hermeneutic approach, using
\end{abstract}

\footnotetext{
${ }^{1}$ Universidade Federal de Goiás (UFG), Goiânia, Goiás, Brasil.
} 
decolonial pedagogy as a political and methodological option, our own reflections, establishing meaningful debates to identify ideas and postures (also political) about the impositions of the West before the indigenous peoples. The proposal established here aims to bring together issues related to the political and commercial systems of the various indigenous communities and the epistemological clashes that constitute these scenarios, as well as to analyze, around interculturality, the historical changes caused by the various segments of the national society.

Keywords: critical interculturality; decoloniality; Indian people; diversity; business.

\section{0 (RE)PENSAR DOS POVOS INDÍGENAS DIANTE DO MUNDO CAPITALISTA}

Historicamente, para a sociedade ocidental dominante, os povos indígenas foram e são vistos como grupos isolados, com culturas ${ }^{2}$ periféricas e marginais. Para Taukane (2003), esses povos são caracterizados, perante os não indígenas, como desfavorecidos, marcados por discriminações, exclusões sociais, explorações, preconceitos e escravidão.

No Brasil, existem diversos povos com representações culturais distintas, línguas e saberes próprios - uma gama de diversidade cultural. Em relação aos povos indígenas, o censo de 2010 do Instituto Brasileiro de Geografia e Estatística (IBGE) esclarece que "[...] o Brasil é composto por 305 etnias indígenas e 274 línguas distintas" (p. 5), com diferentes formas de perceber e lidar com o mundo, já que um mundo sem diversidade é um mundo morto. Nesse viés, as concepções que Taukane (2003, p. 11) discute estão amparadas por uma trama complexa de saberes,

[...] infelizmente existem muitos preconceitos a respeito de nosso povo, talvez pela falta de informação sobre o assunto. Às vezes, o índio, era visto como um selvagem, atrasado e incapaz de lutar por seus direitos, ou como um coitadinho, uma vítima de armação que saía sempre perdendo.

Deparamo-nos com povos que oprimem os povos indígenas desde 1500, com a chegada dos portugueses ao Brasil, que utilizam ideologias as quais buscam

\footnotetext{
2 Para Laraia (2002), o termo "cultura" é um dos temas centrais mais discutidos nos últimos 100 anos pelos antropólogos; o assunto tem se demonstrado inesgotável. O desenvolvimento desse termo é útil para a compreensão do paradoxo da vasta diversidade cultural da humanidade. É complexo: inclui conhecimentos, crenças, arte, moral, leis, costumes ou qualquer outra capacidade ou hábitos adquiridos pelo homem como membro de uma sociedade.
} 
Povos indígenas e as relações culturais, econômicas e políticas: reflexões sobre a interculturalidade crítica e a decolonialidade

romper a diversidade cultural e estabelecem uma cultura maior, na qual os grupos sociais têm os mesmos valores, hábitos, costumes e as mesmas tradições.

Costumes, conhecimentos, mitos, culturas, relações de comércios e línguas dos povos indígenas são frequentemente questionadas pela sociedade não indígena. São poucas as populações que não sofreram influências que, em grande parte, foram estabelecidas por relações de contatos interétnicos com ações que visavam lucrar com a exploração cultural e comercial. Nesse sentido, Barbieri (2014, p. 132) argumenta:

Sabemos que os povos indígenas no Brasil têm um vastíssimo patrimônio cultural, comercial e imaterial, advindo dos seus padrões de comportamentos, símbolos e significados e não têm a verdadeira noção do valor econômico de seus conhecimentos e práticas culturais tradicionais, merecendo maior proteção jurídica.

Assim sendo, surge o propósito de entender essas questões comerciais tanto no contexto indígena quanto nos vários segmentos da sociedade nacional, além da evolução dos processos comerciais; desta forma, (re)pensar as questões sobre os povos indígenas mediante o mundo capitalista, influenciados pelos vários segmentos da sociedade nacional, é comparar as imposições históricas, políticas e econômicas sobre os distintos povos indígenas no Brasil. Nesse sentido, abordaremos concepções pautadas na interculturalidade crítica, fator consistente e abrangente do marco legal no papel dos povos indígenas subalternizados. Nosso objetivo é reunir e problematizar questões relacionadas à diversidade e aos sistemas comerciais dos povos indígenas, e aos embates epistemológicos que constituem esses cenários no Brasil.

No decorrer das últimas décadas, os povos indígenas foram influenciados pelos vários segmentos da sociedade nacional (não indígenas) -, que explora e viola os direitos de grupos distintos. Esses povos foram colonizados ${ }^{3}$ mediante a catequização, comercialização, cujo interesse era sua assimilação e transformação em mão de obra escrava, constituindo um cenário de imenso processo de explo-

3 Para Ramos (2016), no processo de colonização foram impostas aos indígenas, práticas educativas - caráter assimilacionista - que estiveram relacionadas à entrada da Igreja no Brasil. Durante esse período foi utilizada a estratégia de bilinguismo de transição. Os missionários aprendiam as línguas indígenas, para posteriormente traduzir os conhecimentos ocidentais e princípios cristãos para a língua materna dos indígenas. Dessa forma, eram ensinados os princípios do catolicismo e a Língua Portuguesa com o intuito de "pacificar" os indígenas e prepará-los para o mercado de trabalho. 
ração. Submetidos à colonização, não tinham (e ainda não têm) o mesmo direito que os "colonos". No transcorrer da história, esses povos foram vistos e rotulados como grupos desvalidos, vivendo em aldeias isoladas - "primórdios" (SILVA, 2018).

Com o passar do tempo, mudaram-se as leis, todavia, as práticas assimilacionistas que permaneceram foram sendo substituídas pelas práticas integracionistas, que visavam à integração dos indígenas nos projetos de construção nacional (NAZARENO, 2019). Essas ações reforçam o discurso presente nas sociedades capitalistas sobre os distintos grupos indígenas. No trabalho de Ramos (2016), percebemos concepções epistemológicas perante o "ser indígena" no discurso dominante, "ser ou deixar de ser indígena não é condição que está relacionada com a aquisição de bens de consumo utilizados pela sociedade não indígena" (RAMOS, 2016, p. 55).

Essa condição é uma forma opressiva de inviabilizar a identidade, numa concepção superficial que a constrói à luz da associação do indígena ao não indígena. Nessa perspectiva, são estruturados estereótipos para negligenciar primeiro, um processo de dominação e opressão, o qual reproduz a colonização e a exploração comercial. Nessa lógica, os conhecimentos, as práticas comerciais e as várias culturas tradicionais são menosprezadas, considerados subalternos aos conhecimentos do não indígena.

O cenário que se afigura com a chegada do processo de colonização, agentes econômicos, é imprescindível para entendermos o significado da chamada globalização econômica. Esta tem como característica:

I) A ruptura de fronteiras, ou seja, tal ruptura é atribuída à dinâmica do capital, que circula livremente pelo globo, sem respeitar a delimitação de fronteiras;

II) Perda da soberania local, submeter à lógica do capital para conseguir gerar lucros em seus orçamentos;

III) Expansão da dinâmica cultural, o capital se dirige agora às periferias do capitalismo, uma vez que as transnacionais e a colonização Ocidental entenderam que a exploração dos subdesenvolvidos/povos subalternizados promoveria grandes lucros. (PEDROSO, 2012, p. 1).

São poucas as comunidades indígenas que sobrevivem apenas com as relações comerciais tradicionais ${ }^{4}$ intactas e preservadas, advindas do passado. Este

4 Essas práticas comerciais tradicionais são caracterizadas como os artesanatos, as comidas, o escambo, as vestimentas e os hábitos que sofreram drasticamente redução devido à prática capitalista e excludente do discurso e crescimento ocidental. 
Povos indígenas e as relações culturais, econômicas e políticas: reflexões sobre a interculturalidade crítica e a decolonialidade

fato está ligado aos diversos conflitos epistemológicos e históricos dominantes. Em 2003, mais de 85\% das populações indígenas dependiam da agricultura e do "escambo". Com o passar dos anos, as culturas e os conhecimentos indígenas foram explorados pela sociedade não indígena, sem compensações adequadas ${ }^{5}$, e essas populações sofreram (e sofrem) impactos territoriais e embates sociais.

Algumas terras indígenas enfrentam problemas estruturais, políticos e econômicos, os quais abrem caminhos para a inserção em seus cenários, por alguns segmentos da população, que oprimem, exploram e violam os direitos dos demais grupos distintos. Para enfrentar esse problema, é importante remeter-se aos estudos sobre a interculturalidade crítica e a pedagogia decolonial, pois entender os processos econômicos e culturais implica compreender, em parte, a evolução e a inferência dos distintos grupos sociais nas comunidades indígenas.

Conforme Haber (2011), a modernidade ocidental contribui para uma lógica de capital que, na verdade, cria "novas mercadorias". Nesse sentido, as relações comerciais tradicionais dos indígenas foram praticamente eliminadas ${ }^{6}$ ou apropriadas. Entendemos que a dominação também ocorreu no campo das representações, sendo perceptíveis nas comparações de visões de mundo dos indígenas com os ocidentais dominantes. Esta ação advém da natureza opressiva e etnocêntrica, visto que nossa sociedade, "branca", "europeia" "não indígena", "excludente", "capitalista", "monopolista" e "opressora", propende a "padronizar" uma única forma de ser, lidar, manipular, comercializar e de ver o mundo.

O processo de homogeneizar essas formas, com o mundo capitalista e manipulador, esteve presente desde o período de colonização. Este fato se torna perceptível quando Santos (2006, p. 56, grifos do autor) discute as linhas abissais que separam o mundo em dois universos distintos, "como se o lado de cá, dominante, sabe o que é 'melhor' para os que vivem numa outra realidade do lado de lá, oprimidos, que são impostos a aceitarem imagens, culturas e costumes padrões de uma sociedade excludente, explorado".

\footnotetext{
${ }^{5}$ Constitucionalmente os povos indígenas têm o direito à participação legal nos lucros derivados de investimento e obras em suas terras (ANGHER, 2013). A visão de sociedades tuteladas e administradas colonialmente caem por terras, pelo reconhecimento das autonomias das sociedades indígenas e o direito a consulta prévia em seu território.

6 Em alguns casos, essas práticas tradicionais dos povos indígenas foram substituídas pelas ditas "verdadeiras" ou "corretas" vistas pelo mundo ocidental dominador, contradizendo o que está estabelecido na Constituição Federal de 1988.
} 
Essas linhas abissais - dominação hierárquica e separação em dois universos distintos - estão presentes desde o início do processo de colonização no Brasil. As práticas comerciais tradicionais, o "escambo"7 - lado de lá -, realizadas pelos povos indígenas no passado, constituíram-se como objeto de dominação e usurpação, por meio da prática da biopirataria - lado de cá. Essa ação retira desses povos o direito de vivenciar suas relações comerciais tradicionais que, com o passar do tempo, foram modificadas pelo valor monetário.

Essas práticas comerciais tradicionais tornam-se limitadas perante o avanço da globalização e do capitalismo, ocasionando uma perda dos valores tradicionais, patrimônios culturais e imateriais, e a exploração dos recursos oriundos das terras indígenas. Essas limitações provocadas pelos europeus trouxeram consequências para os povos indígenas, uma invasão de suas culturas por um viés hierárquico/ capitalista. A pesquisadora Bond (2010, p. 17-18) mostra a evolução do capitalismo vinculado aos povos indígenas:

A invasão das Américas, nos séculos 15 e 16, envolveu grupos poderosos de vários pontos da Europa. As navegações, na verdade, não foram bancadas apenas pelos reis espanhóis e portugueses e sim também pelas classes ricas de comerciantes, empresários e financistas europeus, com total respaldo da Igreja. O saque do território americano, por tais grupos de poder, é que ajudou a gerar o capitalismo. A América e suas nações indígenas foram invadidas, conquistadas e colonizadas dentro do processo de expansão do capitalismo comercial, o chamado mercantilismo. O roubo das riquezas do Novo Mundo (incluindo a escravização da mão de obra índia) foi o fator mais importante para a acumulação de capitais pela Europa, possibilitando o primeiro passo para o surgimento de uma nova etapa na economia mundial, a chamada revolução industrial. Isto é, o capitalismo moderno, em sua etapa atual de imperialismo, em fase de decomposição, é "herdeiro" daquele que invadiu a América e massacrou seus povos originários. "Este sistema, que desde sempre aplica o lema de Robin Wood ao contrário (tira dos pobres e dá aos ricos), que é o maior responsável pela fome e doenças de milhões de pessoas, além da tão falada crise ambiental de hoje, ligada à poluição das águas e aquecimento do clima, é 'filho' e herdeiro daquele

7 Escambo ou troca direta é a transação em que cada parte entrega um bem ou presta um serviço para receber do outro em forma de crédito, sem que um dos bens seja a moeda, sem envolver dinheiro ou qualquer aplicação monetária em circulação. O escambo inicialmente era utilizado pelos primórdios da colonização portuguesa do Brasil, uma vez que os indígenas não conheciam qualquer outra forma de moeda. 
Povos indígenas e as relações culturais, econômicas e políticas: reflexões sobre a interculturalidade crítica e a decolonialidade

outro. Daquele sistema que, a partir do século 15, provocou o desastre da civilização indígena americana.

Diante dos argumentos acima, por meio da exploração dos recursos comerciais dos povos indígenas como mão de obra do colonizador ocidental, entendemos os motivos que os grupos subalternos vêm sendo excluídos perante o processo e influência "negativa" do capitalismo ${ }^{8}$. Esses fatores só enaltecem o desrespeito social dos povos ditos "descoincidentes". Silva (2018) analisa alguns desses motivos de subalternação e exploração comercial em discussões de alguns indígenas:

Hoje ainda prevalece o sistema escambo, temos a presença da troca tradicional em nossa aldeia, existe o financiamento e empréstimo nas áreas indígenas [...] Isso valoriza o comércio local, a comercialização não está só na aldeia e sim na cidade, na aldeia há troca e na cidade há venda (dinheiro), hoje o escambo prevalece, desde o passado até os dias de hoje [...] O capitalismo chegou na aldeia, influência da tecnologia, muitas vezes o índio faz empréstimo para comprar sua tv, telefone, acontece muito financiamento pelos aposentados, isso supervaloriza o comércio local, muitos comerciantes da cidade não entende o índio, acha que temos muito dinheiro - recebe milhões do governo [...] Isso "engana" o índio, os preços são diferentes para o não indígena e o indígena, os preços são diferentes quando é à vista e a prazo, o sabão custa 2,00 para o não indígena e para o indígena custa 5,00 [...] Queremos que as nossas crianças repassam nossa cultura para seus filhos, para os próximos, devemos conscientizar, mesmo com a evolução, devemos utilizar nossas coisas/artesanatos tradicionais. (SILVA, 2018, p. 46).

Desta forma, é possível perceber os impactos do capitalismo nas aldeias e as supervalorizações de preços pelos comerciantes em vendas voltadas para os povos indígenas. Nos dias de hoje, presenciamos um embate, em que o capitalismo dominou o meio ambiente e a cultura, degradando a biodiversidade e modificando a prática tradicional dos povos indígenas. Podemos observar as desigualdades desta ação para os distintos povos indígenas, que sofrem ataques, saques e explorações em seus territórios, a partir do início do período de colonização do Brasil.

\footnotetext{
8 "Uma vez que o Estado continua a insistir no seu caráter onipotente, apesar do discurso pluralista e democrático. Infelizmente, não houve participação intencional dos povos indígenas na formação do Estado brasileiro [...]" (BARBIERI, 2014, p. 18). A participação não foi intencional, contudo, houve muita influência na formação do Estado. Nos 500 anos de formação do Brasil, sempre se teve que levar em consideração políticas que envolviam os indígenas.
} 
É nesse cenário, como processo colonizador, tecnológico e globalizado, que as relações interculturais foram construídas pelo mundo a partir de movimentos violentos e antidialógicos. Permanece viva a concepção antropológica que compreende a diferença do conhecimento como hierarquia.

Para D’Ambrosio (2000), há uma dicotomia entre o dito "veneno"9 e o "antídoto" ${ }^{10}$ em torno da globalização, do comércio e do capitalismo ao longo do processo histórico. "Conhecer e assimilar a cultura do dominador se tornam positivo desde que as raízes do dominado sejam fortes" (D’AMBROSIO, 2015, p. 23). Já Freire (2014) contribui para afirmar que uma das principais questões com que necessitamos nos preocupar, em relação aos povos indígenas, é como contribuir para que o dominado consiga retirar de si o dominador que o faz "ser invadido", eliminar o caráter exploratório e subalternizante do outro.

Os indígenas são submetidos a uma visão engendrada e advinda dos povos ocidentais opressores. Há um "futuro" prometido, mas que pode se tornar verdadeiro apenas como faceta/marionete do dominador. Nesse contexto, faz-se necessário repensar as lutas políticas, econômicas e epistemológicas com esses povos, que foram silenciados e subalternizados ao longo da história.

O processo de globalização é decorrente do pensamento ocidental dominante, também estruturado pelo pensamento abissal. Esse pensamento atua mediante as linhas abissais que delimitam e separam o mundo humano do subumano - concepções e ideologias preestabelecidas. No tocante ao pensamento abissal, ele reside num sistema de distinções, em "linhas" visíveis e invisíveis que separam a realidade social em dois universos distintos: o "poder dominante" e os "subalternos".

Apesar da riqueza de conhecimentos tradicionais, da complexidade da organização social, das distintas formas de conhecer, sentir e vivenciar o mundo, os indígenas, pela posição que se encontram 'do outro lado da linha', apenas

\footnotetext{
9 Para D'Ambrosio (2000, p. 5), "esse veneno é entendido como uma forma, eficaz, de manter um grupo ou cultura inferiorizado - enfraquecer suas raízes. Remove a historicidade do dominado. Essa é a estratégia mais eficiente para efetivar a conquista".

${ }^{10} \mathrm{O}$ autor supramencionado compreende o antídoto como estratégia mais promissora para a educação/formação - nas sociedades, em que esses grupos sem encontram em transição da subordinação para a autonomia. É restaurar a dignidade de seus indivíduos ou grupos, reconhecendo e respeitando suas raízes culturais e históricas.
} 
Povos indígenas e as relações culturais, econômicas e políticas: reflexões sobre a interculturalidade crítica e a decolonialidade

possuem conhecimentos que, de acordo com a sociedade dominante, são irrelevantes ou incompreensíveis. (RAMOS, 2016, p. 60).

Uma característica fundamental do pensamento abissal é a impossibilidade da copresença dos dois lados desta linha. Para Castro-Gómez (2005), de um lado, estão as culturas do Ocidente (não homogêneas) como parte ativa, criadora e dominadora, e, do outro, estão as demais culturas "receptoras". Essa característica, oriunda dos conhecimentos europeus, é discutida por Santos (2006) quando debate sobre a ecologia de saberes nos mosaicos culturais. Seu entrelaçamento com a pedagogia decolonial proporciona uma visão abrangente daquilo que conhecemos e do que desconhecemos sobre determinados povos ou manifestações culturais.

Os estudos de Santos (2006) sobre a ecologia de saberes designam uma filosofia do conhecimento que parte da heterogeneidade e da globalização contra qualquer forma de supremacia e que contribuem para fortalecer um saber primordial "como é o caso dos saberes religiosos de matriz africana" (p. 2).

Por essa perspectiva, a ecologia de saberes, pensamento pós-abissal, parte do princípio da exclusão social e cultural e da noção de que, enquanto houver essa restrição não será possível uma alternativa pós-capitalista progressista e transformadora. Dessa maneira, são cruciais as contestações entre o conhecimento aprendido e o esquecido, desenvolvido, desprendido e oculto. Enquanto essas linhas invisíveis continuarem a ser erguidas nos contextos indígenas, a luta pelos direitos da não exploração das relações comerciais tradicionais (contradizendo a Constituição Federal de 1988) não terá êxito perante o colonizador.

Ao que tudo indica, para que as lutas dos povos indígenas possam ter resultado, é importante identificar e esclarecer as bases de uma prática transdisciplinar decolonial. Nesse contexto, para Torres (2016, p. 4), essa prática propõe, portanto, a "orientação e suspensão de métodos a partir da decolonização como projeto e como atitude". Quer dizer, degenerar o poder, o ser e o saber constituem parte da consciência decolonial que se alimenta do encontro entre as diversas áreas, manifestando-se numa faceta limítrofe e fronteiriça; algo que vai ao encontro da proposta da interculturalidade crítica estruturada por reflexão e articulação que considere a hermenêutica dos múltiplos saberes existentes e dos postulados científicos.

Uma vez que a interculturalidade crítica abre caminhos para diálogos de diversas formas de saberes e fazeres mediante a ecologia de saberes, apostamos 
nas estruturas que desvelam o papel dos povos indígenas, que passam a fazer parte do meio que os circunscrevem. Associado aos pressupostos supracitados, é salientado o diálogo a partir da etnomatemática, proposto por D’Ambrosio (2013), nas discussões que envolvem o comércio e a cultura dos distintos povos indígenas.

\section{IMPOSIÇÕES HISTÓRICAS E POLÍTICAS CONTRAPONDO AS VISÕES DA INTERCULTURALIDADE CRÍTICA E A DECOLONIALIDADE}

Compreender os conhecimentos indígenas como contribuições às transcendências da humanidade, parte das concepções da interculturalidade crítica e da decolonialidade. Esses campos hermenêuticos de estudo tratam as interpretações culturais a partir das manifestações interculturais, contra o processo de inviabilização e exploração, e constroem, mediante representações da realidade, bem como das ações descolonizadoras das subalternidades, por intermédio de experiências e na vinculação das diferenças culturais, a eliminação do paradigma metafórico - as gaiolas epistemológicas ${ }^{11}$.

Os indígenas, por muitos anos, mediante suas culturas, saberes e relações econômicas, foram "objetos" de exploração comercial, dominação e opressão, pelos não indígenas. Foram colocados no lado de lá da linha abissal - os dominadores não permitem que saiam -, são submetidos aos processos de apropriação e violência. A luta destes povos é sombreada por saberes e concepções políticas e históricas impostas por não indígenas. Para Santos (2006), essas lutas não foram socializadas pela ordem da totalidade das culturas e das racionalidades ocidentais. Quando nos aproximamos desses pensamentos, em termos científicos, percebemos a concessão do monopólio da distinção universal, que provoca uma visão distorcida entre o que é considerado "verdadeiro" e "falso" em virtude da Ciência.

Vários estudiosos, entre eles Castro-Gómez (2005), vêm se preocupando, desde 1970, com o movimento das linhas globais, de tal forma que o outro lado da

\footnotetext{
${ }^{11}$ Esse termo é discutido por D’Ambrosio (2013, p. 80). Para o autor, essa metáfora epistemológica, corresponde, às “disciplinas como conhecimento 'engaiolado' na sua fundamentação, nos seus critérios de verdade e de rigor, nos seus métodos específicos para lidar com questões bem definidas e com um código linguístico próprio, inacessível aos não iniciados".
} 
Povos indígenas e as relações culturais, econômicas e políticas: reflexões sobre a interculturalidade crítica e a decolonialidade

linha parece estar se expandindo, enquanto o lado de cá se encolhe - inferioriza. Para D’Ambrosio (2013, p. 30), uma forma de manter um indivíduo inferiorizado "é enfraquecer suas raízes, remover os vínculos culturais e a historicidade do dominado". Cada ser elabora um subsistema de distinções visíveis e invisíveis, de tal modo que as últimas se tornam o fundamento das primeiras. Logo, remetemo-nos ao monopólio ocidental em torno das epistemologias modernas.

O importante aqui é problematizar, desde a perspectiva da interculturalidade crítica, espaços dialógicos de articulação que considere a hermenêutica dos múltiplos saberes existentes e, com isso, compreender a interação das relações culturais e comerciais das diferentes dimensões dos povos indígenas.

Essas discussões acerca dos comércios, da interculturalidade, das resistências e dos saberes dos povos indígenas chamam a atenção sobre a relação entre a diversidade e a colonialidade do poder. Particularmente, a interculturalidade, compreendida desde os anos 1990, e a pedagogia decolonial, colocam em questão a realidade sociopolítica do neocolonialismo e a dominação epistemológica que estão submetidos os povos indígenas. Desta forma, para Santos (2006, p. 7):

O colonialismo, para além das dominações por que é conhecido, foi também uma dominação epistemológica, uma relação extremamente desigual de saber-poder que conduziu à supressão de muitas formas de saber próprias dos povos e nações colonizados, relegando muitos outros saberes para um espaço de subalternidade.

Ao longo do processo colonial brasileiro, as formas de conhecer e lidar com o mundo capitalista partem das epistemologias dominantes, revogando ou se apropriando de outras formas de perceber e conhecer o mundo com aquelas vinculadas aos povos indígenas. Oliveira e Candau (2010), ao ponderarem a terminologia "colonialidade do poder", proposta por Quijano (2000), concebem-na como uma apropriação do imaginário, que tem como consequência a colonialidade do saber e do ser. Os autores citados mostram outras formas de produção de conhecimento advindo da geopolítica do conhecimento ${ }^{12}$.

\footnotetext{
12 "A geopolítica do conhecimento - assim como a colonialidade do poder, do saber e do ser -, geram tensões apropriadas por Santos (2007) entre regulação/emancipação e apropriação/ violência, as quais coexistem e estão presentes na atualidade, reforçando as linhas abissais" (RAMOS, 2016, p. 71).
} 
Esse entendimento, na perspectiva da ecologia de saberes, é considerado e utilizado no processo de luta e aceitação dos direitos pelos dos povos indígenas. Buscam-se discussões e conhecimentos de formas contra-hegemônica, que se manifestam por meio das concepções da interculturalidade crítica e da decolonialidade. São diversas questões que merecem ser destacadas e levantadas. Entre elas, o que as práticas ocidentais dominantes inferem em seu meio, e como o mundo não indígena tem tratado o problema - subalternação/exploração econômica?

Nesse sentido, Walsh (2007) nos remete a essas informações, ligando-as à característica de uma interculturalidade crítica, que reconhece as diversas formas de lidar com o mundo capitalista não indígena e reconhecer a existência de "manipulações" comerciais, além de questionar e refletir os etnoconhecimentos - as epistemologias do Sul (SANTOS; MENESES, 2010). Saberes e práticas tradicionais no viés da interculturalidade crítica proporcionam outras formas de produzir conhecimentos. De acordo com Nazareno e Freitas (2013, p. 118),

[...] a interculturalidade possui um caráter marcadamente político, visando resgatar a voz e a dignidade dos povos indígenas. Possui, ainda, um caráter de relevância epistemológica, procurando demonstrar como os saberes indígenas podem e devem ser trazidos à tona. Entretanto, não se trata de trazer esses saberes à superfície em uma perspectiva hierarquizante que reforce a subalternidade, mas em condições que apontem para a construção e o pleno reconhecimento de pluri-epistemologias.

Desta forma, torna-se essencial entender a decolonialidade como alternativa e possibilidade para um mundo melhor, com respeito à diversidade e ao outro, desconstruindo-se as fronteiras entre o dito verdadeiro/falso, sentir/pensar. Neste caso, é importante (re)conhecer e (re)pensar as relações comerciais, culturais e os saberes indígenas para além de uma prática hierarquizante. O marco para tal contextualização da interpretação da interculturalidade e diversidade encontram-se na articulação com a pedagogia decolonial.

Para Walsh (2009), essa pedagogia não corresponde a um método, mas a uma opção política. Esta autora discute e faz uma análise sobre as possíveis aproximações entre Frantz Fanon (1961) e Paulo Freire (2004), por não considerar a racialização como base da colonialidade do poder com, em certa medida, análises mais limitadas do que as que são propostas por Fanon. 
Povos indígenas e as relações culturais, econômicas e políticas: reflexões sobre a interculturalidade crítica e a decolonialidade

Na literatura sobre a colonialidade do poder, a temática aparece tanto como descolonialidade e descolonial como decolonialidade e decolonial. Walsh justifica que a supressão do 's' é uma opção sua para marcar uma distinção com o significado do 'des' em castelhano que poderia dar a entender um simples desamar, des-hacer o revestir de lo colonial [...]. (ADAMS, 2015, p. 85 apud WALSH, 2009, p. 24-25).

O interesse em discutir essa pedagogia é, por um lado, com a finalidade de contribuir para o debate das atuais realidades comercial das populações indígenas. Pensar a partir das lutas supramencionadas, é uma perspectiva crítica da interculturalidade, orientada pela transformação, criação, pelo respeito e conhecimento da diversidade cultural - o que assume a visão da decolonialidade.

Desde o início dos anos 1990, algumas discussões sobre as culturas indígenas se transformaram num tema bem complexo. Vários estudiosos começaram a debater sobre tal assunto sem se preocupar com o contexto e o multiculturalismo. A presença e aceitação das discussões sobre o comércio e a decolonialidade na América Latina são resultantes de diversas lutas dos movimentos sociais, que foram os marcos fundamentais para contextualizar esse cenário. Para Walsh (2009, p. 14), essa ligação parte da ideia de colonialidade do poder, "foi estabelecida uma hierarquia racializada: brancos, mestiços e, apagando sua diferença histórica, cultural e linguística, índios, negros, quilombolas, afro-descendentes e outros, como identidades culturais comuns e negativas". O valor humano destes seres, por suas raízes ancestrais, é marcado pela exclusão, que os distancia da sociedade, da prática comercial e das modernidades Ocidentais.

Essa retórica da promoção e aceitação aponta para uma sociedade não indígena preconceituosa, individualista, capitalista, excludente e exploradora. Não existe uma transformação social dos direitos e identidades, e sim a (re)inclusão, na sociedade econômica, dos oprimidos perante a ação do Estado. O enfoque aqui discutido é entendido como um projeto transformador, de caráter ético e político, que valoriza as populações exploradas, entrelaçando as igualdades e o reconhecimento das relações comerciais dos povos originários e as diferenças étnico-raciais. Para Walsh (2009, p. 3), esse enfoque é assumido "como projeto político, social, ético e epistêmico - de saberes e conhecimentos, afirma a necessidade de mudar não só as relações".

A preocupação da autora acima parte da exclusão, negação, exploração, subalternação ontológica e epistêmica dos grupos e sujeitos racializados. Por isso, 
o viés defendido pela autora está em estreita relação com a decolonialidade, a etnomatemática e as relações comerciais indígenas. Ela busca questionar e desafiar essas estruturas sociais da colonialidade e valorizar os saberes e fazeres dos ancestrais. De maneira mais ampla, é um instrumento pedagógico que contradiz a racialidade e os padrões de poder e busca a compreensão e a condição de pensar, agir, estar, ser e viver do outro.

Essas perspectivas se sistematizam como ferramentas que amparam o modo de vida dos oprimidos e concebe-os num novo "projeto" de ser e viver. Por meio destas ideias, Santos (2005, p. 72) menciona a necessidade de criação de "um projeto que provoca questionar as ausências - de saberes, tempos e diferenças", podendo-se entender que esse processo permite ir além das manifestações atuais de uma educação intercultural.

Entender essas questões é perceber como são organizadas e estruturadas as "novas" relações comerciais indígenas, tanto no contexto tradicional quanto na sociedade não indígena e as sobrevivências dos povos historicamente envolvidos. Esse debate comunga com a perspectiva da etnomatemática desde a racionalidade econômica até o desenvolvimento das sociedades antigas em suas organizações de trabalho.

De acordo com Thomson (1974), em algumas sociedades indígenas, os grupos de trabalho eram organizados por relações de parentesco ou por uma divisão "natural", por sexo e idade. Esses membros passavam a se identificar por meio da produção da vida material e comercial. Outros grupos indígenas se estruturavam em torno da produção, comercialização tradicional e do rito mágico, ações essas que organizavam a própria vida econômica. Segundo o autor, a relação entre magia e comércio foi gradativamente sendo distinguida e eliminada por meio das inferências do não indígena e do capitalismo. Essa distinção implicava o reconhecimento da objetividade,

[...] no seixo do processo de produção, o acompanhamento vocal deixa de ser parte integrante e torna-se um sortilégio tradicional que comunica aos trabalhadores as diretrizes apropriadas, e forma-se assim, pouco a pouco, por acumulação, um conjunto de tradições relativas ao trabalho. No rito mágico - mítico, parte vocal serve de comentário à representação que, uma vez separada do trabalho, precisa ser explicada; forma-se um conjunto de mitos...Trabalho e magia ainda se interpenetram, as tradições relativas ao 
Povos indígenas e as relações culturais, econômicas e políticas: reflexões sobre a interculturalidade crítica e a decolonialidade

trabalho estão cheias de crenças míticas e os mitos deixam entrever a sua ligação reconhecível embora longínqua, com os processos de produção. (THOMSON, 1974, p. 61).

Percebe-se, na fala supramencionada do autor, a existência de uma certa consciência da objetividade do mundo exterior, uma categoria inteiramente prática e com pouco poder de abstração. "Pode-se afirmar que por meio de um pressuposto mágico - mítico, foram lançadas as bases para a subalternização do outro e, consequentemente, de suas formas de saber" (NAZARENO; CARDOSO, 2013, p. 247).

\section{MEDO SE APOSSOU E TROUXE “GUERRAS" SEM SENTIDO: DUAS CONTRAPARTIDAS DA COLONIALIDADE}

Em algumas pesquisas, questionam-se o princípio dos impactos da modernidade em relação aos povos indígenas, "consequência da economia capitalista". Essa ideologia se apoia em suas facetas, desde o século XVI, no período mercantilista. Para Castro-Gómez e Grosfoguel (2007), a lógica da colonialidade não é questionada; o que acontece é a omissão do questionamento dada a Modernidade.

O posicionamento decolonial é simultâneo à Modernidade, pressupondo a diferença como marco e impulso para a compreensão desta. A partir da invasão da América, por meio do contato do colonizador com os povos indígenas, africanos e afrodescendentes, houve uma expansão para outros continentes, como Ásia e África. Esse pensamento começou a trilhar sua própria genealogia: conforme Castro-Gómez e Grosfoguel (2007), o pensamento colonial foi diferindo da teoria e dos estudos pós-coloniais ${ }^{13}$.

O argumento básico do posicionamento decolonial é a ideia de que se desprende do poder colonial/capital e se abre perante as manifestações interculturais, encoberto pela racionalidade moderna. É nesse sentido que Grosfoguel (2007) o diferencia das teorias pós-coloniais. Em consequência da formação e da instauração da matriz colonial do poder ocidental, e de seu desprendimento, é

${ }^{13}$ Obras/autores pós-coloniais - Provincializing Europe (2000) do historiador indiano Dipesh Chakrabarty e Histórias locais/Projetos globais: 7 colonialidade, saberes subalternos e pensamento liminar (2003) do sociólogo argentino Walter Mignolo. Essas obras forneceram importantes contribuições para a constituição da singularidade da crítica de cada um desses movimentos. 
que Quijano (1992) propôs o giro epistêmico decolonial ${ }^{14}$. Em uma de suas publicações, o autor acima descreve essa conjunção da modernidade/colonialidade da seguinte forma:

La crítica del paradigma europeo de la racionalidad/modernidad es indispensable. Más aún, urgente. Pero es dudoso que el camino consista en la negación simple de sus categorías; en la disolución de la realidad en el discurso; en la pura negación de la idea y de la perspectiva de totalidad en el conocimiento. Lejos de esto, es necesario desprenderse de las vinculaciones de la racionalidad-modernidad con la colonialidad, en primer término, y en definitiva con poder no constituido en la decisión libre de gentes libres. Es la instrumentalización de la razón por el poder colonial, en primer lugar, lo que produjo paradigmas distorsionados de conocimiento y malogró las promesas liberadoras de la modernidad. La alternativa, en consecuencia, es clara: la destrucción de la colonialidad del poder mundial. (QUIJANO, 1992, p. 437 apud, CASTRO-GÓMEZ; GROSFOGUEL, 2007, p. 28).

O reconhecimento das diversas populações subalternizadas possibilitou o dito, "giro epistêmico", ao perceber que, "a pluralidade e o plurilinguismo deveriam ser acrescentados à perspectiva pluri-epistemológica" (NAZARENO; CARDOSO, 2013, p. 246). Neste sentido, Lages (2010) oferece subsídios importantes para a análise de nosso problema, o autor ressalta como uma expressão cultural/comercial subalternizada pode incorporar razões que exprimem as divergências, excedendo a lógica do poder capitalista, que viola os direitos dos demais grupos distintos.

O giro epistêmico parte do reconhecimento da colonialidade do poder como um dos elementos estruturantes da matriz colonial de poder. A colonialidade visa à hierarquização das diferenças, dos saberes, dos comércios e dos fazeres. Para Nazareno e Cardoso (2013, p. 246), a partir dela são estabelecidas "condições para o soerguimento de uma civilização, logocêntrica, androcêntrica e eurocêntrica".

Uma pergunta fundamental que se pode levantar é: o que significa falar de "giro epistêmico" em relação às concepções de interculturalidade crítica e decolonialidade, no debate acerca das questões comerciais indígenas? Essas duas perspectivas representam uma sequência que é provida pela diferença e

\footnotetext{
${ }^{14}$ Para Adelia Miglievich-Ribeiro (2014, p. 69), "giro epistêmico é indissociadamente um movimento teórico, ético e político ao questionar as pretensões de objetividade do conhecimento dito científico dos últimos séculos e, no que nos diz respeito diretamente, das ciências sociais".
} 
Povos indígenas e as relações culturais, econômicas e políticas: reflexões sobre a interculturalidade crítica e a decolonialidade

que é consequência dos impactos das modificações, do comércio no passado e no presente, das populações indígenas.

Pela perspectiva do não indígena não poderia ser diferente. Para justificar tanta exploração dos recursos e do comércio destes povos, foi necessária a criação de um espaço totalmente metafísico de modo a realçar as margens do capitalismo/ dominador - usufruir de benefícios indevidos. A resistência é anterior à data de cinco séculos, as populações indígenas passaram a criar estratégias de visibilidade dos impactos da colonialidade, e as grandes mobilizações, construiriam uma estrutura étnica de políticas de resistência, alterando a percepção generalizada dos subalternos.

É importante destacar que o processo decolonial, a partir da perspectiva da interculturalidade crítica, fornece as concepções de colonialidade do poder, é um paradigma "outro", que questiona e modifica essa colonialidade, ao mesmo tempo, mostrando as faces visíveis desta. O pensamento decolonial tem por finalidade a (de)colonialidade do poder do capitalismo diante dos povos indígenas (da matriz colonial do poder), processo que obteve contribuições de Quijano (1992, p. 447 apud, CASTRO-GÓMEZ; GROSFOGUEL, 2007, p. 30):

En primer término [es necesaria] la decolonización epistemológica, para dar paso luego a una nueva comunicación ínter-cultural, a un intercambio de experiencias y de significaciones, como la base de otra racionalidad que pueda pretender, con legitimidad, a alguna universalidad. Pues nada menos racional, finalmente, que la pretensión de que la específica cosmovisión de una etnia particular sea impuesta como la racionalidad universal, aunque tal etnia se llama Europa occidental. Porque eso, en verdad, es pretender para un provincianismo el título de universalidad.

(Re)pensar esse processo significa refletir sobre os momentos de (des)colonização, "capitalistas - prática consumista", históricos/evolutivos e do conhecimento do ser, instâncias que foram esquivas e reduzidas pela modernidade/colonialidade de modo a eliminar formas de contato e diálogo mais verdadeiros e plurais.

Observamos as grandes desigualdades e inferências do capitalismo nas relações comerciais dos vários povos indígenas, destinadas às minorias étnicas e excluídas, como povos alheios aos processos desenvolvimentistas. Desde a chegada de Colombo no Caribe, em 12 de outubro de 1492, e posteriormente no Brasil, em 1500, os povos indígenas sofreram (e sofrem) com a exploração de seus territórios, comércios e bens imateriais - interesses governamentais. 
Esses interesses buscaram um novo mercado rentável que retira bens comerciais e recursos de terras e saberes indígenas, além de retirar os sonhos de uma comunidade culturalmente tradicional e negligenciar os benefícios das relações econômicas tradicionais para os povos indígenas. Desta forma, Silva (2018, p. 51) traz uma importante fala de um indígena para compreender essas relações:

Imaginamos que no futuro prevalecerá o escambo - nosso sonho é ter as coisas do passado no futuro, não queríamos muitas coisas que geram doenças no presente no futuro [...] o capitalismo está dentro das comunidades e gera doença e desvaloriza nossa cultura.

Associado ao patrimônio comercial, biocultural e ao processo colonial, é importante reconhecer o vasto patrimônio que possuí nosso país. Observa-se a utilização inadequada dos conhecimentos tradicionais indígenas, ainda que o artigo 216, inciso III, da Constituição Federal de 1988, estabeleça incentivos e valorizações para as produções e os conhecimentos de bens e valores culturais.

O direito indígena, proposto pela Constituição, abarca a natureza coletiva dos povos pelo usufruto exclusivo de seus recursos, suas terras e trocas comerciais. Esses povos possuem direitos sobre os recursos genéticos e materiais presentes em suas terras, ligados ou não ao conhecimento ancestral, além de opinar nas mudanças comerciais e culturais e as influências ocidentais dentro de suas terras.

Uma questão importante que apontamos é a alienação/usurpação das relações comerciais praticadas em contextos indígenas pela sociedade envolvente e a transferência dos benefícios aos grupos locais, já que são os indígenas que ocupam as áreas de grande riqueza genética e fauna de nosso país. O dilema é o reconhecimento do valor individual, e também coletivo, de seu patrimônio e garantir-lhes o direito à escolha e aos benefícios, dado que a Constituição de 1988 não reconhece o usufruto dos recursos genéticos, mas só o identifica após a validação presente no artigo 231. A verdade é que os conhecimentos indígenas são uma fonte infindável para o mercado consumidor do Ocidente, que visa ao potencial de lucro.

Desta forma, sugerimos que os povos indígenas busquem posicionamentos para que possam participar e conduzir os desenvolvimentos econômicos e das escoIhas das relações comerciais e políticas em suas comunidades, mantendo suas identidades livres e preservadas perante os demais segmentos da sociedade nacional. 


\section{A LUTA DAS POPULAÇÕES DOMINADAS DIANTE DO IMPACTO ECONÔMICO NO PROCESSO COLONIAL}

Segundo Castro-Gómez (2005), a colonialidade do poder ${ }^{15}$ é uma esfera de análise que traça parâmetros em relação a uma estrutura específica de dominação e exploração, implementada nas colônias americanas a partir de $1492^{16}$; é uma relação fundada na suposta superioridade ética e cognitiva dos europeus.

Para Haber (2011), essa violência (impacto) do colonialismo econômico reprime, constitui e governa os povos indígenas - cria um "novo mundo colonial". Esse "mundo" está cercado por linguagens, posturas, concepções e atitudes impostas que reprimem, negam e silenciam o outro.

Nessa matriz de poder, não se trata somente de submeter militarmente os povos indígenas e dominá-los com o uso de força ou de exploração, senão fazer uma mudança radical nas formas tradicionais de conhecer o mundo e lidar com a realidade circundante, adotando como próprio do horizonte cognitivo o campo do dominador. Quijano (1992 apud, CASTRO-GÓMEZ, 2005) descreve a colonialidade do poder como uma colonização dominada: a representação recai num modo de perceber e construir conhecimentos e significados. Para superar esse problema da colonialidade, é fundamental indisciplinar a Antropologia - buscar uma razão decolonial para os problemas comerciais subalternos. Nesse sentido, Schiwy e Walsh (2007, p. 13-14) afirmam que

[...] indisciplinar significa desatar as fronteiras das ciências sociais que cercam a produção e distribuição do conhecimento. Implica o reconhecimento de outras formas de conhecimento, particularmente os conhecimentos locais [...]. Propõe romper com as tendências modernistas das ciências sociais que distanciam e dividem o sujeito e o objeto do conhecimento. (SCHIWY; WALSH, 2007apud SUÁREZ-KRABBE, 2011, p. 186).

\footnotetext{
${ }^{15}$ Para Quijano (2000, p. 7), “a colonialidade do poder está vinculada com a concentração na Europa do capital, dos assalariados, do mercado de capital, enfim, da sociedade e da cultura associadas a essas determinações. A industrialização através da substituição de importações é, na América Latina, um caso revelador das impliçaç̃es da colonialidade do poder".

16 "Os processos de integração regional em curso hoje na América Latina têm sido marcados por uma lógica territorial que tem concebido grandes áreas do espaço geográfico latino-americano como 'vazios demográficos' ou 'terras disponíveis'. Essa forma de conceber o espaço geográfico latino-americano remonta ao legado colonial que atravessa a formação socio-espacial da região e a própria posição que o continente americano ocupou no processo de formação do sistema-mundo moderno-colonial, a partir de 1492" (CASTRO-GÓMEZ, 2005, p. 40).
} 
Em outras palavras, indisciplinar requer uma aproximação política com o excluído, eliminar a violência epistêmica ${ }^{17}$, saber como estudar e lidar com a realidade a ser transformada - é importante, neste caso, desaprender nossas próprias teorias e ideias de cientificidade para reconhecer a hipótese e a visão com quem se trabalha ou estuda, em companhia deste.

É fundamental ainda abandonar os enfoques do capitalismo que nos cercam, (re)pensar a Ciência, reconhecer a importância dos indígenas e de seu papel no cenário mundial e a influência do capitalismo. O mundo está cheio de exclusão, exploração, opressão e violência que o capitalismo se alimenta. O pensamento decolonial não busca somente um mundo melhor para os que são subalternizados, senão lutar contra as condições de sofrimento, exploração e discriminação, incluindo aquelas situações das quais fazemos parte.

A diversidade evolui como adaptação em seu entorno e, dentro de uma determinada cultura, existe um conjunto de "traços culturais" que são diretamente influenciados por outros fatores econômicos e culturais. Há práticas comerciais e culturais que não são reconhecidas e não têm valor perante as sociedades ocidentais dominantes. É importante estudar os processos envolvidos e históricos e entender o mundo ao redor, passo fundamental para estudar as relações comerciais indígenas e sua diversidade na construção social (SILVA; RIBEIRO, 2019).

Precisamos nos remeter aos três passos da investigação decolonial para (re) conhecer os diversos impactos sobre o comércio dos povos indígenas, que são influenciados pelo capitalismo, "reconhecer" e "aprender" (aprender a aprender), (re)aprender e "solidar" - (saber conhecer/ajudar o outro, e se ajudar).

Uma estratégia para a superação das problematizações indígenas, em transição da subordinação para a autonomia, é que os demais segmentos da sociedade nacional (não indígenas) restaurem, respeitem, cooperem e solidarizem com a dignidade dos outros indivíduos culturalmente distintos - reconhecendo suas raízes históricas, os saberes e fazeres tradicionais, a paz e os princípios éticos.

A partir desse pensamento, é fundamental refletir e (re)pensar as transformações econômicas mais contextualizadas e comunitárias nos contextos indígenas. As problematizações apresentadas aqui, sobretudo aquelas relativas ao comércio

17 "Violência epistêmica", para Suárez-Krabbe (2011), é a alteração, a negação em casos extremos - como as colonizações, extensões dos significados da vida cotidiana. 
Povos indígenas e as relações culturais, econômicas e políticas: reflexões sobre a interculturalidade crítica e a decolonialidade

dos povos indígenas diante dos outros segmentos da sociedade nacional, apontam para novas visões, concepções, possibilidades e perspectivas sobre o impacto mundial em que esses povos estão inseridos.

Refletir sobre a importância das relações comerciais nas comunidades indígenas voltadas à interculturalidade crítica, decolonialidade e a ecologia de saberes, a partir do Sul, será um ganho que assenta aos vários conhecimentos aqui presentes. Ao mesmo tempo, significa uma compreensão acerca do papel dos povos indígenas diante das sociedades ocidentais dominadoras. É possível perceber a pluralidade de informações em nosso cenário.

\section{CONSIDERAÇÕES E CAMINHOS POSSÍVEIS QUE SURGEM}

As problematizações voltadas à interculturalidade crítica, decolonialidade e a ecologia de saberes vieram ao encontro de nossas inquietações acerca das questões que articulam elementos culturais, epistêmicos, materiais e simbólicos ligados ao papel das mudanças culturais e econômicas dos povos indígenas brasileiros. Nesse cenário, surge uma enorme diversidade cultural, com modos próprios de enxergar o meio e o mundo capitalista.

Buscamos refletir sobre as interpretações históricas nas relações comerciais dos povos indígenas que estabelecem relações preconceituosas e exploratórias perante os não indígenas. O diálogo aqui construído à luz da antropologia proporcionou significativas argumentações reflexivas sobre as relações comerciais indígenas. A partir das discussões voltadas à interculturalidade, pudemos compreender um pouco sobre a realidade cultural, social e econômica vivenciada pelos povos indígenas e os impactos/influências "negativas" a partir do que descrevem os próprios indivíduos sobre cultura ocidental dominante.

Essas reflexões são decorrentes da matriz de poder proposta por Quijano (2000), não se trata somente de submeter militarmente os povos indígenas e dominá-los com o uso de força ou de exploração de seu comércio, senão fazer uma mudança radical nas formas tradicionais de conhecer o mundo e lidar com a realidade circundante, adotando como próprio do horizonte cognitivo o campo do dominador. Para Rousseau (1989, apud CABRAL, 2016), é a própria sociedade não indígena a responsável pela desigualdade, subalternação, injustiça e arbitrariedade comerciais existentes. 
Ao nosso ver, o importante é compreender o "desconhecido", problema esse para o qual não se tem uma compreensão única. Acreditamos que o debate sobre as relações comerciais, culturais e políticas, em cenários interculturais, produz e socializa novos conhecimentos. O que esperamos é que se cumpram as leis prescritas pela Constituição Federal de 1988 e se reconheçam os distintos povos indígenas, bem como a promoção de autonomias para que eles possam enfrentar as várias transformações econômicas e políticas em diversas situações vividas.

Entendemos que a leitura sobre o outro busca a valorização das relações de poder e proporciona um novo olhar para o capitalismo. Para que as lutas dos povos indígenas possam ter resultado, é importante identificar e esclarecer as bases de uma prática transdisciplinar decolonial. Dessa forma, a abordagem à luz da interculturalidade crítica e da decolonialidade tornou-se fundamental, pois possibilitou caminhos aos debates outros sobre as práticas comerciais e culturais, que as fortificam em prol dos valores pertencentes às populações indígenas. Por conseguinte, percebe-se que as relações comerciais tradicionais estão em processo de transformação e subalternação, caminhando na direção contrária à interculturalidade. Nesse sentido, a problematização do comércio com a cultura tradicional revitaliza e potencializa a preservação do conhecimento dos povos indígenas.

\section{REFERÊNCIAS}

ADAMS, T. Pedagogias decoloniais: práticas insurgentes de resistir, (re)existir y (re)vivir. Revista em educação popular e educação básica, v. 10, n. 2, p. 34-45, 2015.

ANGHER, A. J. Vade mecum: acadêmico de direito. São Paulo: Rideel, 2013.

BARBIERI, S. R. J. Biopirataria e povos indígenas. São Paulo: Almedina, 2014.

BOND, R. História do caminho de Peabiru. 1. ed. Rio de Janeiro: Ediouro, 2010.

CABRAL, J. F. P. Rousseau: desigualdade e contrato. Brasil Escola, Uol, 2016. Disponível em http://brasilescola.uol.com.br/filosofia/rousseau-desigualdade-contrato.htm. Acesso em: 22 jan. 2018.

CASTROS-GÓMEZ, S. La hybris del punto cero: ciencia, raza e ilustración en la Nueva Granada. Bogotá: Editorial Pontifícia, 2005. 
Povos indígenas e as relações culturais, econômicas e políticas: reflexões sobre a interculturalidade crítica e a decolonialidade

CASTRO-GÓMEZ, S.; GROSFOGUEL, R. El giro decolonial: reflexiones para una diversidad epistémica más allá del capitalismo global. Bogotá: Siglo del Hombre Editores, 2007.

CENSO BRASILEIRO DE 2010. IBGE, Rio de Janeiro, 2010.

D’AMBROSIO, U. Educação para sociedade em transição. 2. ed. Campinas: Papirus, 2000.

D’AMBROSIO, U. Etnomatemática em movimento. 2. ed. Belo Horizonte: Autêntica Editora, 2013.

D’AMBROSIO, U. Etnomatemática: elo entre as tradições e a modernidade. 5. ed. Belo Horizonte: Autêntica Editora, 2015.

FANON, F. Los condenados de la tierra. México: Fondo de Cultura Económica, 1961/2001.

FREIRE, P. Pedagogy of indignation. 2. ed. Colorado: Paradigm, 2004.

FREIRE, P. Pedagogia da autonomia: saberes necessários à prática educativa. 49. ed. Rio de Janeiro: Paz e Terra, 2014.

HABER, A. Nometodología payanesa: notas metodologia indisciplinada. Chile Antropologia Revista, Catamarca-Chile, n. 23, p. 9-49, 2011.

LARAIA, R. B. Cultura: um conceito antropológico. 15. ed. Rio de Janeiro: Jorge Zahar Ed., 2002.

LAGES, S. R. C. Saúde da população negra: reconhecimento e tradução cultural no terreiro de Umbanda. 2010. Tese (Doutorado em Psicossociologia de Comunidades e Ecologia Social) - Universidade Federal do Rio de Janeiro (UFRJ), Rio de Janeiro, 2010.

MIGLIEVICH-RIBEIRO, A. Por uma razão decolonial: desafios éticos-políticosepistemológicos à cosmovisão moderna. Plural, São Paulo, n. 1, p. 204-21, 2014.

NAZARENO, E.; FREITAS, M. T. U. Interculturalidade e práticas pedagógicas contextualizadas: uma perspectiva de-colonial para a formação de professores/as indígenas. In: PIMENTEL, M. S.; BORGES, M. V. (Org.). Educação Intercultural: experiências e desafios políticos pedagógicos. Goiânia: PROLIND/SECAD-MEC/FUNAPE, 2013.

NAZARENO, E.; CARDOSO, L. S. Crítica do dualismo ontológico racionalista Ocidental a partir da Decolonialidade e da Enación. Fragmentos de cultura, Goiânia, v. 3. n. 3, p. 245-54, 2013. 
NAZARENO, E. O estado e as políticas linguísticas adotadas como estratégicas na formação da nação brasileira a partir do século XVI. In: XAVIER, L. O.; ÁVILA, C. F. D.; FONSECA, V. (Org.). A qualidade da democracia no Brasil: questões teóricas e metodológicas da pesquisa. 4. ed. Curitiba: CRV, 2019. p. 299-317. V. 4.

OLIVEIRA, L. F.; CANDAU, V. M. F. Pedagogia decolonial e educação antirracista e intercultural no Brasil. Educação em Revista, Belo Horizonte, v. 26, n. 1, 2010, p. 15-40.

PEDROSO, I. V. C. P. Globalização, comércio mundial e formação de blocos econômicos. Educação, Globo.com, 2012. Disponível em: http://educacao.globo.com/artigo/ globalizacao-comercio-mundial-formacao-de-blocos-economicos.html. Acesso em: 2 set. 2017.

QUIJANO, A. Coloniality of power and its institutions. Nova lorque: Binghamton University, 1992.

QUIJANO, A. Colonialidade do poder, eurocentrismo e América Latina. Buenos Aires: Consejo Latinoamericano de Ciencias Sociales, 2000.

RAMOS, G. C. Sistema de numeração e pinturas corporais Javaé: a etnomatemática por uma relação dialógica entre cultura e educação escolar. 2016. Dissertação (Mestrado em Educação em Ciências e Matemática) - Universidade Federal de Goiás, Goiânia, 2016.

SANTOS, B. P. Freire e Ubiratan D'Ambrosio: contribuições para a formação do professor de matemática no Brasil. 2007. Tese (Doutorado em Educação) - Universidade de São Paulo, São Paulo, SP, 2007.

SANTOS, B. S. El milenio huérfano: ensayos para una nueva cultura política. 2. ed. Madrid: Editora Trotta, 2005.

SANTOS, B. S. Para além do pensamento abissal: das linhas globais a uma ecologia de saberes. Novos Estudos CEBRAP, São Paulo, n. 79, p. 71-94, 2006.

SANTOS, B. S.; MENEZES, M. P. Epistemologias do Sul. São Paulo: Editora Cortez, 2010.

SCHIWY, F.; WALSH, C. Indisciplinar las ciencias sociales: geopolíticas del conocimiento y colonialidad del poder. Quito: Abya Yala/Universidad Andina Simón Bolívar, 2007.

SILVA, M. M. Etnomatemática e relações comerciais na formação de professores indígenas. 2018. Dissertação (Mestrado em Educação em Ciências e Matemática) - Universidade Federal de Goiás, Goiânia, GO, 2018. 
Povos indígenas e as relações culturais, econômicas e políticas: reflexões sobre a interculturalidade crítica e a decolonialidade

SILVA, M. M.; RIBEIRO, J. P. M. Críticas e preconceitos ocidentais em contraposição às formas de aculturação e concepções ameríndias. Tellus, Campo Grande, MS, v. 19, n. 40, set./dez., p. 187-202, 2019.

SUÁREZ-KRABBE, J. En la realidad: hacia metodologías de investigación descoloniales. Tabula rasa, Bogotá, n. 14, jan./jun., p. 183-204, 2011.

TAUKANE, E. B. Minha formação, meu povo: um só objetivo. In: Taukane, E. B. Caderno de Educação Escolar Indígena, Barra do Bugres, v. 2, n. 1, p. 11-8, 2003.

TORRES, N. M. Transdisciplinaridade e decolonialidade. Revista Sociedade e Estado, Brasília-DF, v. 31, n. 1, p. 75-97, 2016.

THOMSON, G. Os primeiros filósofos. 1. ed. Lisboa: Estampa, 1974.

WALSH, C. Interculturalidad y colonialidad de poder: un pensamiento y posicionamiento "otro" desde la diferencia colonial. In: GÓMEZ, S. C.; GROSFOGUEL, R. El giro decolonial: reflexiones para una diversidad epistémica más allá del capitalismo global. Bogotá: Siglo del Hombre Editores, 2007. p. 47-62.

WALSH, C. Interculturalidade crítica e pedagogia decolonial: in-surgir, re-existir e re-viver. In: Candau, M. V. (Org.). Educação intercultural na América Latina: entre concepções, tensões e propostas. Rio de Janeiro: 7 Letras, 2009. p. 12-42.

\section{Sobre os autores:}

Matheus Moreira da Silva: Doutorando e mestre em Educação em Ciências e Matemática pela Universidade Federal de Goiás (UFG). Graduado em Licenciatura em Matemática pelo Instituto de Matemática e Estatística (IME) da UFG. Colaborador no Programa de Educação Tutorial da Licenciatura Intercultural (PETLI/UFG) e no curso de Educação Intercultural do Núcleo Takinahaky de Formação Superior Indígena (UFG). Tem experiência na área de Matemática, com ênfase em Educação Matemática, atuando principalmente nos seguintes temas: Etnomatemática, Didática, Prática de Ensino, Formação de Professores, Diversidade Cultural, Relações Étnico-Raciais e Educação Escolar Indígena. E-mail: matt.moreira.pet@gmail.com, ORCID: https://orcid.org/0000-0002-3925-6527

José Pedro Machado Ribeiro: Doutor em Educação pela Universidade de São Paulo (USP). Mestre em Matemática pela Universidade de Brasília (UnB). Bacharel em Matemática pela Universidade Federal de Goiás (UFG). Professor do Instituto de Matemática e Estatística (IME) da UFG. Coordenador do Laboratório de Educação Matemática do IME/UFG. Tem experiência na área de Educação, 
com ênfase em Etnomatemática, atuando principalmente nos seguintes temas: Etnomatemática, Educação Matemática, História da Matemática, Educação Escolar Indígena, Formação de Professores, Diversidade Cultural, Matemática aspectos sociais e dinâmica intra e intercultural. E-mail: zepedro@ufg.br, ORCID: https://orcid.org/0000-0002-9227-3908

Elias Nazareno: Pós-doutor em Sociologia com bolsa do CNPq pela Universidade de Barcelona (UB). Doutor em Sociologia pela UB. Mestre em História pela Universidade de Brasília (UnB). Graduado em História pela Pontifícia Universidade Católica de Goiás (PUC-Goiás). Pesquisador associado sênior vinculado ao Laboratório e Grupo de Estudos em Relações Interétnicas (LAGERI) do Departamento de Antropologia da UnB. Professor do Programa de Pós-Graduação em História da Universidade Federal de Goiás. E-mail: eliasna@hotmail.com, ORCID: https://orcid.org/0000-0002-9689-9721

Recebido em: 6 de março de 2020.

Aprovado para publicação em: 27 de julho de 2020. 